\title{
Comparison between Famous Game Engines and Eminent Games
}

\author{
Prerna Mishra and Urmila Shrawankar
}

\author{
Department of Computer Science \& Engineering, RTMNU, Nagpur (MS), India
}

\begin{abstract}
Nowadays game engines are imperative for building 3D applications and games. This is for the reason that the engines appreciably reduce resources for employing obligatory but intricate utilities. This paper elucidates about a game engine, popular games developed by these engines and its foremost elements. It portrays a number of special kinds of contemporary game developed by engines in the way of their aspects, procedure and deliberates their stipulations with comparison.
\end{abstract}

Keywords - Game Engine, Non-Cloud Gaming Platforms, Cloud Gaming Platforms, Popular Games, GPGPU

\section{INTRODUCTION}

$\mathrm{I}_{\mathrm{i}}^{\mathrm{N}}$ $\mathrm{N}$ general, the notion of game engine is very easy to comprehend. It is a platform for performing game related tasks like interpretation, physics related reckoning, and to facilitate developers for focusing on the niceties that make the game inimitable. Engines are in reality an assemblage of reusable modules that can be manipulated in order to carry a game towards realism. Indeed, there are certain disparities between a game and a game engine [1]. Graphics, animation, audio, physics, UI and AI are the major different constituents of an engine. Conversely the subject matter of a game, its definite characters and background, real world avatar and its behaviours etc. are the components that create the real game. Game engines are middleware's.

Game engines produce the replication of actual world in the digital world by controlling the elementary physics. Games developed by these engines make user, casual or die-hard player. In general, smartphone operators, as mobile game players, are alike casual gamers rather than die-hard gamers. In contradiction of die-hard gamers, casual gamers are outlined as less dedicated, less spirited, and more tranquil users. Casual gamers incline to be not as much of ardent and less fascinated to classy or multifarious games (comparative to gameplay, achieve target, environs, graphics, chaps, etc.).The market for video games is growing, with sales in 2015 of $\$ 91.5$ billion marking an $11.84 \%$ increase over 2014, at this price global revenues are expected to reach $\$ 107$ billion in 2017. However, growth is not only in sales but also in the miscellany of matter offered, vacillating from scholastic games to first-person shooters. In addition, a captivating conjunction of mass media is proceeding with video games, having motion picture eminence cut-scenes and voiceover.

In a cloud environment, the task of service provider is separated into two: the infrastructure providers managing cloud platforms and rent assets conferring to a usage, and service providers leasing assets from one or more infrastructure providers to assist the users. Lately, a novel type of cloud service has been familiarized, which have the utmost severe exigencies on network Quality of Service (QoS) to date known as cloud gaming. However, in cloud gaming the complete user experience is provided through the network. This creates dissimilarity between cloud gaming and conventional online Gaming in stipulations of network quality of experience (QoE). While in conformist Online Gaming the user experience is spawned at the client side so the network does not have any impact on the performance, affecting the worth of Cloud Gaming $[2,4]$

With the constituent of video gaming disappearing, people merely favour to finance time in real-time mobile games that are compatible with an extensive array of platforms and operating systems. These engines takes the gaming experience to an entirely new-fangled echelon, avoiding poor graphics and quality experiences with the similar joysticks from the past to play around.

This paper portrays the comparative study of few diverse cloud and non-cloud platforms that are currently associated with gaming. As games are evolving progressively delivering profounder and added a biding experience for players, their prospective for psychosomatic impression is growing in proportion. Some renowned companies of games are Microsoft Game Studios, Electronic Arts, etc [3]. Console producers are a company yielding and disseminating video game consoles. Some of the utmost familiar console producers are Atari, Microsoft Corporation, Nintendo Company, Sega, and Sony Computer Entertainment Inc. However, currently there are three major popular platforms Microsoft Xbox 360, Sony PlayStation3 and Nintendo apart from mobile gaming apps as shown in figure 1 .

\section{Comparative Study}

\section{A. Non-Cloud Platform Stage}

Analysis amid numerous game engines is a daunting errand for the reason that of their innumerable field, kinds, hypermedia sustenance, middleware support, language and platform enslavements and many other deputized characteristics. It has to be acknowledged that the noncloud game platforms have dissimilar features, modules, benefits and restrictions relating some eminent game engines. Six popular game engines are compared with each other namely Cry Engine 3, Hero Engine, Source 2 Engine, Unity 4 Engine, Unreal Engine 4 and Vision Engine 8.Table 1 expresses the efficacy in terms of platform reliance, interface and language, intrinsic physics and AI engine supported with forward and backward compatibilities.

An analysis was completed with the help of 15 students (beginner coders) and 20developers from different game industries who gave their views on a number of game engines currently accessible in the marketplace in India. Figure 1 depicts the popular gaming platforms in India.

\section{B. Cloud Gaming Platforms}

A cloud gaming [5-7] structure assembles the participant's activities, transfers it to the cloud server, concocts the act, extract the consequences, and conceals the resultant modifications into the gaming simulating environment and rivulets the gaming sequences in return to the player. 
TABLE 1

ASSESSMENT OF ENGINES ON PERFORMANCE ASPECTS

\begin{tabular}{|c|c|c|c|c|c|c|}
\hline Game Engine & Platforms & $\begin{array}{c}\text { Language } \\
\text { Support }\end{array}$ & AI Engine & $\begin{array}{c}\text { Physics } \\
\text { Engine }\end{array}$ & $\begin{array}{c}\text { Forward } \\
\text { compatibility }\end{array}$ & $\begin{array}{c}\text { Backward } \\
\text { compatibility }\end{array}$ \\
\hline CryEngine 3 & $\begin{array}{c}\text { Win, X360, } \\
\text { PS3, Wii U }\end{array}$ & $\begin{array}{c}\text { C++, } \\
\text { Visual } \\
\text { Script, Lua }\end{array}$ & Lua-driven AI & Soft-body & No & Yes \\
\hline Hero Engine & Win & Hero Script & AIseek & PhysX & Partial & Yes \\
\hline Source 2 Engine & $\begin{array}{c}\text { Win, Mac, Xbox 360, Wii, Linux, } \\
\text { Android }\end{array}$ & C++ & AI Director & Ipion & Partial \\
\hline Unity 4 & $\begin{array}{c}\text { BlackBerry, Win Phone, Win, OS } \\
\text { X, Android, iOS, Apple TV, PS3/4, } \\
\text { PS Vita, Xbox 360, Xbox One, Wii } \\
\text { U, Wii. }\end{array}$ & $\begin{array}{c}\text { C\#, JavaScript, } \\
\text { Boo }\end{array}$ & RAIN & PhysX & Partial & Yes \\
\hline \multirow{2}{*}{ Unreal 4 Engine } & $\begin{array}{c}\text { Windows, OS X Linux, Xbox 360/ } \\
\text { One, PS3/4, Wii U, Android, iOS, } \\
\text { WinRT, PS Vita }\end{array}$ & $\begin{array}{c}\text { C++, C\#, GLSL, } \\
\text { CG, HLSL }\end{array}$ & Kynapse & PhysX & Partial & Yes \\
\hline Vision Engine 8 & $\begin{array}{c}\text { Windows, Xbox 360, PS3, Wii, Wii } \\
\text { U, iOS, Android, Win Phone, PS Vita }\end{array}$ & C++ & Kynapse & $\begin{array}{c}\text { Bullet, } \\
\text { ODE, } \\
\text { PhysX }\end{array}$ & No & Partial \\
\hline
\end{tabular}

For safeguarding inter communication, all the sequential actions tends to happen in a period of milliseconds. Subliminally, the total time, which can be said as communication interruption or delay, essentially are kept negligibly conceivable for delivering an amusing involvement to cloud game players. One of the modest methodologies for supporting cloud gaming is to use the services of general desktop streaming thin clients, such as Ubitus, GamingAnywhere [6], and VirtualGL.

\section{Game Development Platform Popularity}

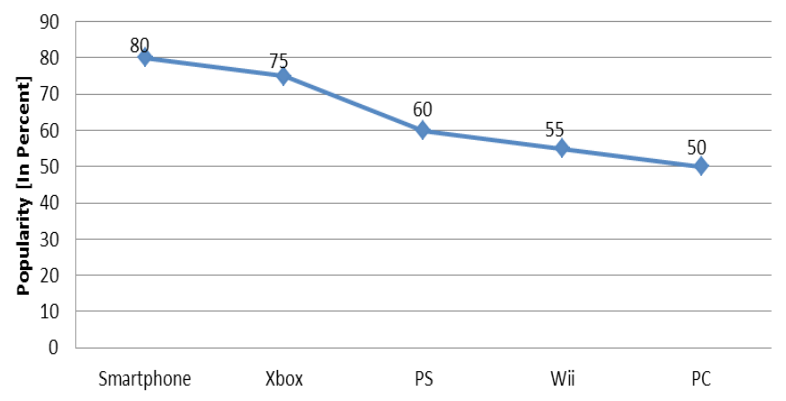

Fig 1. Popularity of gaming platforms in India

Cloud gaming not only necessitates elevated continual downlink bandwidth but low latency too [5-7]. Cloud gaming by now has engendered a prodigious contract of curiosity amongst business persons, venture investors, and the end users. Some prominent cloud platforms are discussed below.

\section{1) Gaikai}

In GaiKai, games are uploaded to the datacenters situated largely around the globe. From these centers, they are cascaded using high-end servers to the devices connected to each other by medium of internet, analogous to the manner videos are streamed to the user's computer. It endows the capability of streaming the graphically rich and real games and additional related data rapidly to more or lessons any devices from anywhere in the world. Gaikai has developed the utmost excellence; quickest communicating cloud-streaming platform on the globe, aiding a platform to developer's proficient enough for providing games and other communicating matter instantaneously to the end users via the Internet. Nevertheless Gaikai do not sustain packages on devices like digital TVs and tablets

\section{2) StreamMyGame}

StreamMyGame [6] is a wide-ranging software elucidation that empowers games and applications to be played remotely. One accesses and plays games tenuously via their local/home network. This gaming platform gains access and engages in gameplay tenuously by means of their broadband network, note downs gameplay to High definition Video archives, one can upload recorded HD video files to any online video sites and publicize games, so anybody on their native system can perceive it and participants gets access to amenities of meeting other players by means of creating the groups with forums, chats, recognize new and former participants presence.

\section{3) OnLive}

OnLive [5] conveys on request real-time communal experiences with opulent content via the Internet. OnLive uses cloud to deliver the potency and astuteness needed to immediately convey comprehensive applications having animations, graphics, AI, physics, etc.

OnLive make use of virtual machines on customized servers with graphics processing units (GPUs) and commercial compression procedures, which has to work-out two issues for game respectively. Live stream is augmented for gameplay depending on physicalworld Internet circumstances and Media stream is a server-side full HD stream managing viewers or players for recording and reviewing progressions of their games. In spite of the benefits, Onlive has quite a few restrictions. Actually OnLive is not reasonably noble enough for accomplishing 1080p resolution. That is to say for the reason that it requires broadband speediness of up to $10 \mathrm{MB}$ per second.

\section{4) GamingAnyWhere}

GamingAnyWhere is the paramount open-source game development platform [6]. It concedes scholars to experiment notions and concepts on a cloud gaming proving-ground, gaming bringers to cultivate services on it and player scan fabricate their personal gaming clouds from their computers [11]. Moreover, of its candidness, it is designed for high affability, maneuverability, and re-assessability. Platforms supported by GamingAnyWhere are Windows, Linux, and OS X, iOS and Android. GamingAnyWhere is multi-platform, proficient in footings of time and space complexities and offers accessible unrestricted platform. 


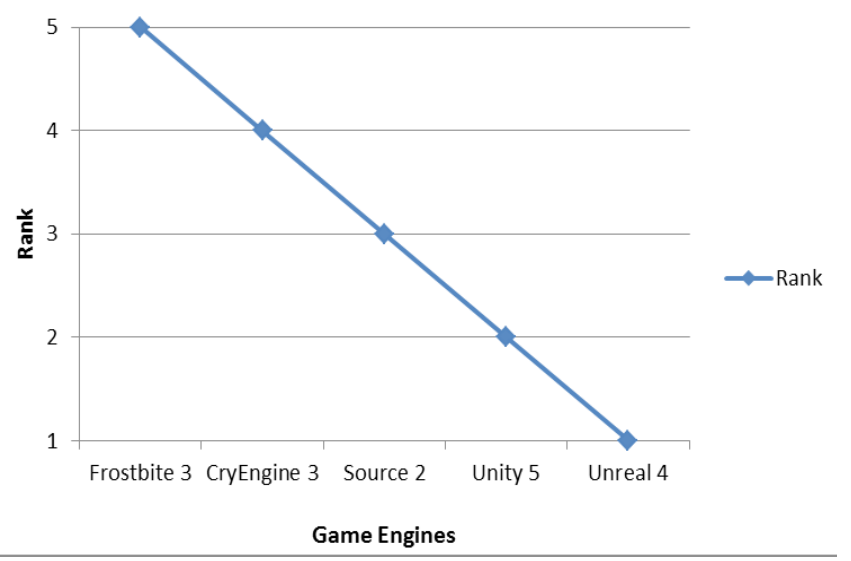

Fig 2. Best Game Engines for Developers as per usability

\section{TESTING}

Impact and efficiency of game engines were tested against the most famous games developed using these game engines. Every game is unique on its own and has set the benchmark for other similar games. The games taken for testing are:

- Cry Engine: Crysis 3

- Source Engine: Counter Strike Global Offensive

- Hero Engine: Star Wars The Old Republic

- Unity Engine: Assassin's Creed

- Unreal Engine: Batman Arkham City

- Vision Engine: Max Payne 3

Most popular and best six games stated above were compared to each other on theirGPU usage and its efficiency to operate high end graphics, their CPU utilization and memory usage. These three testing drive are explained in detail.

For testing, four standard budget GPU's i.e. GE Force GTX 680, Radeon HD 7870, GE Force GTX 670 and Radeon HD 7970 are used. These GPU's were tested on two different dual core CPU's namely, Intel Core i7-3770k and AMD FX-8150. The games were tested at two common desktop display resolutions: 1680x1050, 1920x1200, using normal and very high quality settings respectively.

\section{A. GPU Performance}

For Max Payne, attaining the target frame rate of 80fps was arduous at $1680 \times 1050$ than expectation. This called for the utilization of either the GeForce GTX $670 \mathrm{Ti}$ or Radeon HD 7870 which averaged $77 \mathrm{fps}$ and 70fps respectively. Radeon HD 7870 declined the desired target framerate with 77fps. Graphics cards such as the GE Force GTX 680, GE Force GTX 670 and Radeon HD 7970 managed to achieve the average by $108 \mathrm{fps}, 101 \mathrm{fps}$, and $87 \mathrm{fps}$ respectively. At 1920x1200, it takes the Radeon HD 7870 to surpass an average of 80fps. The Radeon HD 7970 averaged 100fps being consistent with the GeForce GTX 670 which exceeded by $22 \mathrm{fps}$. In the meantime, the GeForce GTX 680 and Radeon HD 7970 both scored 134fps and $87 \mathrm{fps}$ as shown in figure 3 and figure 4.

Comparing Star Wars: The Old Republic (SWTOR) to all GPUs shows that, Star Wars: The Old Republic requires a graphics card that is capable of DX 9 or OpenGL 4.1. It is seen that star wars executes best compared to other games. All of the cards in these graphs deliver more than a 90 FPS minimum at 1680x1050 and 80fps at 1920x1080, a playable result across the panel The Radeon cards impede behind similarly-priced GeForce panels.
Testing Crysis 3 at $1680 \times 1050$ on medium quality depicted that GTX 680 toped the graph with 79fps, while the GTX 670 trailed closely with $75 \mathrm{fps}$ and the HD $7970 \mathrm{GHz}$ edition delivered 70fps, $3 \mathrm{fps}$ than the usual7970.At 1920x1200, Radeon HD 7970 or GTX 670 is needed for an average of $60 \mathrm{fps}$, while the GTX 680 is compulsory for an attempt to break the 60fps hurdle. On the contrary HD 7870 failed to reach the average fps.

Starting by the top of the graph, it can be seen that GTX 680 and Radeon 7970 for Batman Arkham City, averages a 36fps. While the GTX 670 R9 290 performs unpersuasively, delivering an average of 30fps. Ardently GTX 680 and RD 7970 tops the chart being the suitable high value performance GPU at 1680x1050.Moving further, in the graph it is observed, the RD 7970 delivered playable performance along with the GTX $6804.0 \mathrm{GHz}$ Edition. The old GTX 670 also performed quite well, despite dipping down to $45 \mathrm{fps}$ at times.

The Assassin's Creeds thrives to match up the intensity, pushing the GTX 680 to its edge at $1680 \times 1050$. It is observed that GTX 680's framerate is fully playable in ACU. Performance declined slightly for Radeon 7970 and GTX 670 but the smoothness and efficiency of motion is appreciative even for the scarcely perceptible fps drops for GTX users. At 1920x1200, everything until the GTX 680 perseveres at playable framerate. Certain graphics optimization adjusts on the GTX 670 enables an amalgam high-medium setup with playable framerates.

The limited hardware requirement is one of the robust benefits of Counter Strike: Global Offensive (CS: GO). Even if with Intel's former HD Graphics 3000, multiplayer mode is feasible depending on the resolution at lower or normal settings. Midrange GPU's such as the GeForce GTX 680 deals with higher details and $2 \times$ anti-aliasing qualities with no tribulations for $1680 \times 1050$ avoiding the need a high-end GPU at all. These settings are promising with the GeForce GTX 670. For the newest fervent levels of GPUs like the Radeon HD 7970M and the GeForce GTX 670M, Counter Strike does not appear to pretense any confront.

\section{B. CPU Performance}

On testing the games on quad and octa-core processors, it is seen, high CPU utilization across quad processors, while those with eight cores spreads the load equally well and evenly depicted on figure Y.

Crysis 3, Core $17-3770 \mathrm{~K}$ at its default clock frequency of $4.0 \mathrm{GHz}$, impelled the GTX 680 to a mellifluously flowing to $69 \mathrm{fps}$, but on overclocking to $4.5 \mathrm{GHz}$ profits more frames and gets a $37 \%$ growth of the total of $95 \mathrm{fps}$ for GTX panel. Similar fashions is seen with the AMD FX-8150 but since the chip already comes clocked at $4.0 \mathrm{GHz}$, it does not leave much margin. Effortlessly it managed to increase the average frame rate from $80 \mathrm{fps}$ to $85 \mathrm{fps}$ thus giving better play experience as shown in figure 5.

For beginners, it is much desirable to use a quad-core processor, by preference a latest Core i7 or the FX-8150. Additionally, more likely there is a need of dual GTX 680s or HD $7970 \mathrm{GHz}$ versions in order to play with high settings at $1920 \times 1200$ or more. For the classic regular game player, the preeminent graphics card for playing Crysis 3 is the GTX 670, as only one card delivers an average of 70fps even at $1920 \times 1200$.

Although Batman: Arkham City is extremely demanding on Virtual RAM. If sufficient VRAM is accessible, the game uses about $4.2 \mathrm{~GB}$ 's at $1080 \mathrm{p}, 5 \mathrm{~GB}$ at $1440 \mathrm{p}$ and a slightly above $6 \mathrm{~GB}$ at $4 \mathrm{~K}$. This might be the reasons triggering several performance disputes for those who are executing on lower-end hardware. Heavy CPU utilization is witnessed across quad-threaded processors; the Core i7 presented a real astonishment by delivering a consonant performance giving 89 fps which is reasonable. However FX 8150 executed rather poorly on comparison with core i7. It provided highest of $79 \mathrm{fps}$ when 


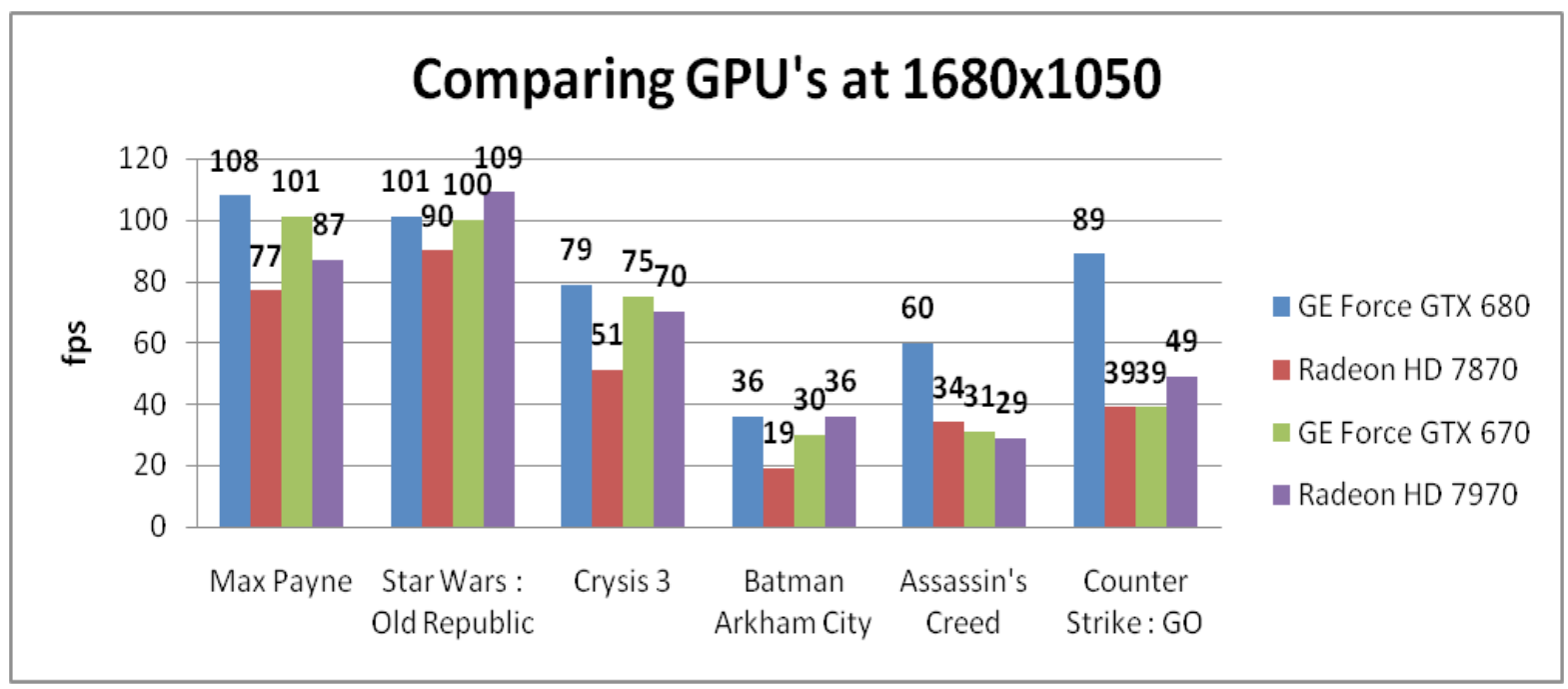

Fig 3. GPU performance at resolution 1680x 1050

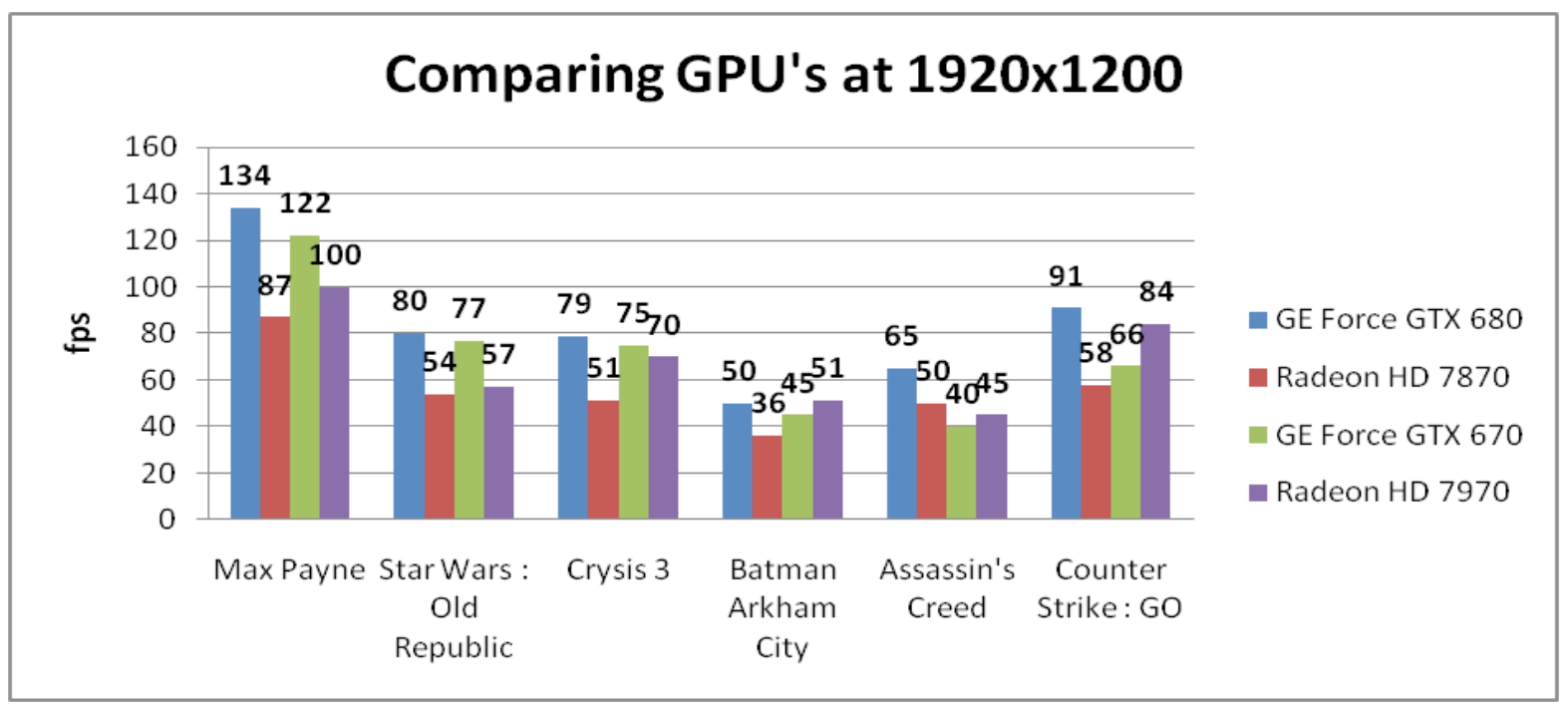

Fig 4. GPU performance at resolution 1920x 1200

overclocked, touching the average of core i7.

Although Batman: Arkham City is extremely demanding on Virtual RAM. If sufficient VRAM is accessible, the game uses about $4.2 \mathrm{~GB}$ 's at $1080 \mathrm{p}, 5 \mathrm{~GB}$ at $1440 \mathrm{p}$ and a slightly above $6 \mathrm{~GB}$ at $4 \mathrm{~K}$. This might be the reasons triggering several performance disputes for those who are executing on lower-end hardware. Heavy CPU utilization is witnessed across quad-threaded processors; the Core i7 presented a real astonishment by delivering a consonant performance giving 89 fps which is reasonable. However FX 8150 executed rather poorly on comparison with core i7. It provided highest of 79fps when overclocked, touching the average of core i7.

For core 17 in Max Payne, there was a minimal variation in the fps at default clock frequency giving peak of $70 \mathrm{fps}$ but this variation rose in the case of FX-8150. Radeon panel gave $75 \mathrm{fps}$ providing better play to user. But GTX performed poorly giving only $61 \mathrm{fps}$. Overall it can be concluded that, the averages appear playable.

Counter Strike: Global Offensive is CPU heavy game, utilizing much of CPU it can. It can reach high fps over 90 and by no means dropping below $70 \mathrm{fps}$ on most areas on both the processors. Core i7 gave consistent performance though FX-8150 had consonant but improved performance on the GPU's.
Assassin's Creed on core i7 at default clock frequency, gives $90 \mathrm{fps}$ thus making the game intensely playable. But FX 8150 performed poorly when overclocked, manages to give average of $60 \mathrm{fps}$.

Unfortunately, Star Wars Old Republic foiled to even reach $60 \mathrm{fps}$, with averages of $58 \mathrm{fps}$ and $59 \mathrm{fps}$ at 1680x1050 and 1920x1200, respectively. The only system that hit the $60 \mathrm{fps}$ average was Intel Core i7with the GTX GeForce 680 builds, which hit $61 \mathrm{fps}$ as lowest. At $4.5 \mathrm{GHz}$, the FX series is nearly capable to meet the Intel Core i7 processors. Core i7 is able to reach the peak on GTX 680 at just $2.5 \mathrm{GHz}$, while the FX-8150 involves its full $5 \mathrm{GHz}$ express ascent clock frequency to attain the equal point.

In the situation of quad-core chips, to enable fast and liquefied multitasking, gleaming 2D/3D gameplay, and super-rapid camera presentation, among other things, each core can be put to work concurrently on a particular job. Current octa-core chips merely have two sets of quad-core processors, which split several tasks between them accordingly. Many a times, the set of cores which are lowpowered will be assigned tasks. With the need of advanced tasks, eventually, the set of faster four cores will take effect.

It is always influenced by the power-per-core and its architecture. For example, Intel quad cores are about the same as AMD octa-cores, because of the architecture and the separate cores have more influence. 


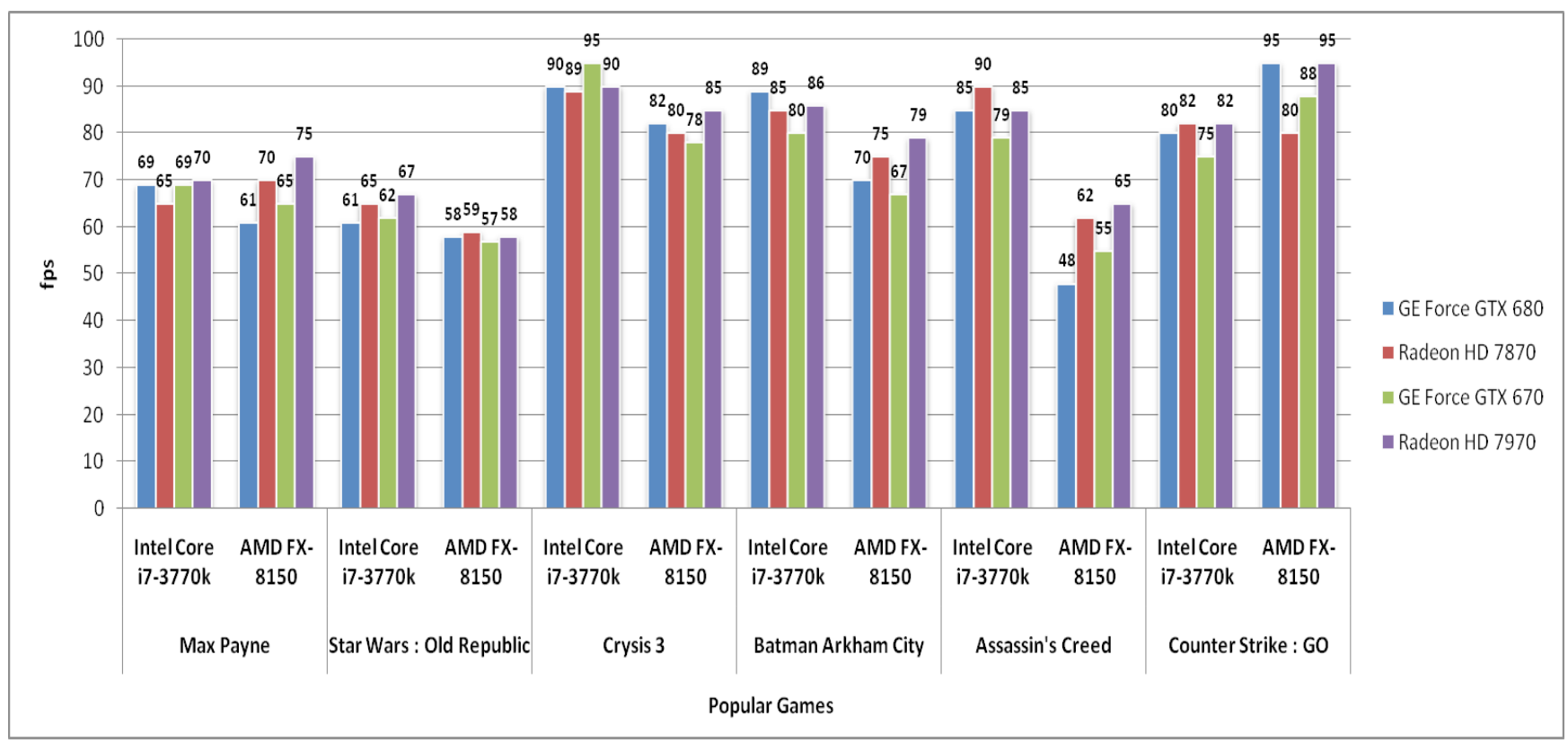

Fig 5. CPU performance of games for four selected GPU's

\section{Memory Usage}

It was equally essential to check the memory required communally for these games to run smoothly and effectively. On both aspects, minimum required memory and recommended memory availability should be taken into account while playing the games, for the reason that lack of available memory might cause the system to run leisurely while actively playing these games. Table 2 shows the assessment between memory usage by these games.

Overall it can be seen that minimum requirements of all games are satisfactory but Max Payne proves to be memory effective in case of HDD. Along with Max Payne, batman and crysis3 uses 2 GB RAM but both these games are reasonable for HHD required. On the other hand, Assassin's creed proves to be very affordable.

TABLE 2

MEMORY REQUIREMENT BY GAMES

\begin{tabular}{|c|c|c|}
\hline Games & $\begin{array}{c}\text { Minimum } \\
\text { Requirement }\end{array}$ & $\begin{array}{c}\text { Recommended } \\
\text { Memory }\end{array}$ \\
\hline CS: GO & $\begin{array}{c}1 \text { GB RAM } \\
7.6 \text { GB HDD }\end{array}$ & $\begin{array}{c}2 \text { GB RAM } \\
7.6 \text { GB HDD }\end{array}$ \\
\hline Max Payne 3 & $\begin{array}{l}2 \text { GB RAM } \\
35 \text { GB HDD }\end{array}$ & $\begin{array}{c}3 \text { GB RAM } \\
35 \text { GB HDD }\end{array}$ \\
\hline Assassin's Creed & $\begin{array}{l}1 \text { GB RAM } \\
8 \text { GB HDD }\end{array}$ & $\begin{array}{l}1 \text { GB RAM } \\
8 \text { GB HDD }\end{array}$ \\
\hline SWTOR & $\begin{array}{c}1 \text { GB RAM } \\
15 \text { GB HDD }\end{array}$ & $\begin{array}{l}4 \text { GB RAM } \\
15 \text { GB HDD }\end{array}$ \\
\hline Batman & $\begin{array}{c}2 \text { GB RAM } \\
18 \text { GB HDD }\end{array}$ & $\begin{array}{c}4 \text { GB RAM } \\
18 \text { GB HDD }\end{array}$ \\
\hline Crysis 3 & $\begin{array}{c}2 \text { GB RAM } \\
20 \text { GB HDD }\end{array}$ & $\begin{array}{c}8 \text { GB RAM } \\
20 \text { GB HDD }\end{array}$ \\
\hline
\end{tabular}

IV. Empirical Study As Per Views Given By Gamers

Various game devotees and intensive players were asked to give their comments and judgment on these games. A Google form was created and players were asked to submit their opinion for the game based on certain criteria stated below. Table 3 shows the overall comparative analysis of games on the basis of comments sent by them.

It can be seen that, people admires playing Batman Arkham City, Assassin's Creed and Crysis 3. These games have tremendous followers around the world as they offer intensive graphics, high image quality and enmeshing music

\section{Role Of GPGPU In Games}

GPUs are potent processors dedicated to graphics computation, much faster than CPU on considering all the parallel processors. With the advancements of programmable GPUs has facilitated new potential for general purpose GPU computation (GPGPU) which is used to embellish the altitude of realism in virtual gaming simulations.

Mostly GPGPU accords only with graphics steps of the game loop, while the CPU processes primarily utmost of the game logic. This work diverges from the conventional approach; GPU offers practical implementation of the entire game loop. This is indeed a leap for gaming world, as the CPU's are advancing towards multi-core processors thus imminent games needs related parallelism as in the case of GPU programs.

Contemporary GPUs are fully programmable many-core chips build up roundabouts an array of lateral processors. GPU has scalable array of multithreaded Streaming Multiprocessors (SM), each of which is competent enough to support thousands of inmate parallel hardware threads. Each SM here is a collection of processors. A multiprocessor executes the same instruction on a these assembly of threads at every clock cycle, thus called as warp. To handle such a bulky number of threads, it utilizes an exclusive scheme called SIMT (SingleInstruction, Multiple-Thread). The thread management consisting of creation, scheduling, and synchronization is performed entirely within hardware by the SM with basically zilch cost.

Existing GPUs consist of a huge number of splinter processors with high memory bandwidth. By several form, the current 
TABLE 3:

COMPARATIVE EVALUATION OF GAMES

\begin{tabular}{|c|c|c|c|c|c|c|}
\hline & CRYSIS 3 & STAR WARS:OR & Max Payne & Assassin's Creed & $\begin{array}{c}\text { Batman Arkham } \\
\text { City }\end{array}$ & Counter Strike: GO \\
\hline $\begin{array}{l}\text { Graphic } \\
\text { quality }\end{array}$ & $\begin{array}{l}\text { Stunning and crisp } \\
\text { textures but more visually } \\
\text { pleasing in } 1080 \mathrm{P}\end{array}$ & $\begin{array}{l}\text { Blumy at } 720 \mathrm{p} \text { but } \\
\text { enjoyable at } 1080 \mathrm{p}\end{array}$ & Impressive graphics & Good & Astonishing graphics & Normal graphics \\
\hline Art Style & Visually rich & $\begin{array}{l}\text { Blend of realistic and } \\
\text { more animated styles }\end{array}$ & $\begin{array}{l}\text { Gothic but incredible } \\
\text { art style }\end{array}$ & $\begin{array}{l}\text { Striking art style with } \\
\text { smooth and satisfying } \\
\text { movement }\end{array}$ & $\begin{array}{l}\text { Modem Hyperrealism } \\
\text { style }\end{array}$ & $\begin{array}{l}\text { Art style is mixed with the } \\
\text { real world and replicates real- } \\
\text { world finishing well }\end{array}$ \\
\hline Story & $\begin{array}{l}\text { Crysis 3's revolves around } \\
\text { Prophet, a Nanosuit holder } \\
\text { who is on a quest to take } \\
\text { revenge on the CELL } \\
\text { Corporation, and the } \\
\text { Alpha Ceph, the leader of } \\
\text { the Ceph alien race. }\end{array}$ & $\begin{array}{l}\text { Story builds on an } \\
\text { ensemble cast, part and } \\
\text { parcel to Star Wars' movie } \\
\text { charm }\end{array}$ & $\begin{array}{l}\text { Max investigates on } \\
\text { a case related to his } \\
\text { family murder and } \\
\text { finds himself framed } \\
\text { in a murder }\end{array}$ & $\begin{array}{l}\text { Two linked story. One is } \\
\text { of an Assassin who want } \\
\text { to find the "Apple of } \\
\text { Eden", and other is of a } \\
\text { person in the present } \\
\text { who's experiencing the } \\
\text { assassin's memories }\end{array}$ & $\begin{array}{l}\text { The main storyline } \\
\text { revolves around } \\
\text { Batman's imprisonment } \\
\text { in Arkham City later } \\
\text { stopping the chaos } \\
\text { created by Joker }\end{array}$ & $\begin{array}{l}\text { Each player joins either the } \\
\text { Terrorist or Counter-Terrorist } \\
\text { team and attemptsto complete } \\
\text { objectives or eliminate the } \\
\text { enemy team. }\end{array}$ \\
\hline $\begin{array}{l}\text { Pacing of } \\
\text { story }\end{array}$ & Pacing is very slow & $\begin{array}{l}\text { Well-paced story, likeable } \\
\text { original characters }\end{array}$ & $\begin{array}{l}\text { Game pace keeps } \\
\text { moving forward } \\
\text { speedily }\end{array}$ & Well paced story & Insanely tight pacing & Fairly consistent pace \\
\hline $\begin{array}{l}\text { Character } \\
\text { emotional } \\
\text { development }\end{array}$ & $\begin{array}{l}\text { Convincing enough to } \\
\text { have emotional attachment } \\
\text { to the character and face } \\
\text { decisions }\end{array}$ & $\begin{array}{l}\text { Emotional attachment to } \\
\text { your character and face } \\
\text { decisions in the game } \\
\text { which will guide the } \\
\text { development of your } \\
\text { character and determine } \\
\text { the direction of the } \\
\text { character's storyline }\end{array}$ & $\begin{array}{l}\text { Max is relentless and } \\
\text { even makes you feel } \\
\text { his pain. Good facial } \\
\text { expressions and } \\
\text { emotions. }\end{array}$ & Minimal cold emotion & $\begin{array}{l}\text { Subtle emotional } \\
\text { responses on the } \\
\text { characters faces }\end{array}$ & $\begin{array}{l}\text { Minimal } \\
\text { involvement }\end{array}$ \\
\hline Customization & $\begin{array}{l}\text { Weapon and equipment's, } \\
\text { multiplayer character } \\
\text { customization }\end{array}$ & $\begin{array}{l}\text { UI, Character and } \\
\text { companion customization }\end{array}$ & $\begin{array}{l}\text { Character and } \\
\text { multiplayer avatars } \\
\text { customization }\end{array}$ & $\begin{array}{l}\text { Character, equipment } \\
\text { and outfit customization }\end{array}$ & $\begin{array}{l}\text { Customize playing } \\
\text { modes }\end{array}$ & $\begin{array}{l}\text { Customization of crosshair, } \\
\text { in-game text, view model, the } \\
\text { mini map }\end{array}$ \\
\hline $\begin{array}{l}\text { Ability to } \\
\text { modify game } \\
\text { with ease }\end{array}$ & $\begin{array}{l}\text { On unlocking suits, } \\
\text { players has an advantage } \\
\text { over his enemies by using } \\
\text { the suit's enhanced } \\
\text { strength, r stealth } \\
\text { capabilities to modify } \\
\text { gaming actions }\end{array}$ & $\begin{array}{l}\text { Ability to switch factions } \\
\text { with modified base game } \\
\text { storyline }\end{array}$ & $\begin{array}{l}\text { Modifications can } \\
\text { perform several } \\
\text { functions, such as the } \\
\text { ability to add new } \\
\begin{array}{l}\text { weapons, skills, } \\
\text { perspectives, } \\
\begin{array}{l}\text { surroundings, and } \\
\text { characters }\end{array}\end{array}\end{array}$ & $\begin{array}{l}\text { Chest piece reduces the } \\
\text { ability of guards to see } \\
\text { the hero to a specific } \\
\text { percentage. One can add } \\
\text { options to equip the } \\
\text { assassin's ability }\end{array}$ & $\begin{array}{l}\text { Ability to change } \\
\text { predator challenge }\end{array}$ & $\begin{array}{l}\text { Modification can be done on } \\
\text { completion of tasks }\end{array}$ \\
\hline Gameplay & $\begin{array}{l}\text { The gameplay of Crysis } 3 \\
\text { is almost exclusively about } \\
\text { killing }\end{array}$ & $\begin{array}{l}\text { The social gameplay and } \\
\text { challenging, puzzle } \\
\text { combat. The project's key } \\
\text { focus is to differentiate } \\
\text { amid the player's faction } \\
\text { and morality }\end{array}$ & $\begin{array}{l}\text { Max Payne } 2 \text { is a } \\
\text { third-person shooter, } \\
\text { in which the player } \\
\text { assumes the role of } \\
\text { Max Payne }\end{array}$ & $\begin{array}{l}\text { Jacob and Evie Frye, } \\
\text { assassin twins who } \\
\text { come to London in } 1868 \\
\text { to dismantle the } \\
\text { Templar conspiracy }\end{array}$ & $\begin{array}{l}\text { Batman is devoted to } \\
\text { protect city from crime }\end{array}$ & $\begin{array}{l}\text { Modem-military first-person } \\
\text { shooter game }\end{array}$ \\
\hline \begin{tabular}{l|} 
Smooth \\
transition \\
between story \\
and gameplay \\
sequences
\end{tabular} & $\begin{array}{l}\text { Seamlessly transition } \\
\text { between story and action } \\
\text { sequences by the input } \\
\text { controller }\end{array}$ & $\begin{array}{l}\text { Nice flow and has the } \\
\text { ability to queue up } \\
\text { multiple actions in a } \\
\text { sequences }\end{array}$ & $\begin{array}{l}\text { Story sequences } \\
\text { bleed directly into } \\
\text { gameplay } \\
\text { wonderfully telling } \\
\text { story between actions }\end{array}$ & $\begin{array}{l}\text { Smooth transition } \\
\text { between story and } \\
\text { gameplay, splitting the } \\
\text { story between both } \\
\text { characters }\end{array}$ & $\begin{array}{l}\text { A gap between story } \\
\text { and action }\end{array}$ & Seamless transition \\
\hline $\begin{array}{l}\text { Good } \\
\text { Ending/Few } \\
\text { loose ends }\end{array}$ & $\begin{array}{l}\text { Prophet, the hero is alive } \\
\text { and thinks to live peaceful } \\
\text { life by hiding his } \\
\text { identification glaning } \\
\text { gameplay bugs, the bow is } \\
\text { very powerful making too } \\
\text { easy to play }\end{array}$ & $\begin{array}{l}\text { Story ends in a different } \\
\text { place than shown in the } \\
\text { movie. The ending is } \\
\text { dumb }\end{array}$ & $\begin{array}{l}\text { It has a sad ending, } \\
\text { max is left all alone/ } \\
\text { Has glitches and } \\
\text { other technical } \\
\text { problems }\end{array}$ & $\begin{array}{l}\text { The competitive } \\
\text { multiplayer component } \\
\text { acts as a loose end }\end{array}$ & $\begin{array}{l}\text { Realistic story/ some } \\
\text { missions need to be } \\
\text { downloaded by intemet }\end{array}$ & $\begin{array}{l}\text { Counter-Strike is an entirely } \\
\text { multiplayer experience. One } \\
\text { can play offline against AI } \\
\text { bots }\end{array}$ \\
\hline $\begin{array}{l}\text { Difficulty of } \\
\text { game }\end{array}$ & $\begin{array}{l}\text { Once selected a difficulty } \\
\text { level, one can jump to } \\
\text { lower difficulty level only } \\
\text { The five difficulty levels } \\
\text { in order of easiest to } \\
\text { hardest are: Recruit, } \\
\text { Soldier, Veteran, Super } \\
\text { soldier, and Post-Human } \\
\text { Wamior }\end{array}$ & $\begin{array}{l}\text { They come in Nomal, } \\
\text { Difficult, Elite and Boss } \\
\text { difficulties. Each level } \\
\text { increases the difficulty in } \\
\text { space mission }\end{array}$ & $\begin{array}{l}\text { The Max Payne } 3 \\
\text { Story can be played } \\
\text { at five difficulty } \\
\text { settings that can be } \\
\text { adjusted on the fly } \\
\text { and provide varying } \\
\text { levels of challenge: } \\
\text { easy, medium, hard, } \\
\text { hardcore and old } \\
\text { school }\end{array}$ & $\begin{array}{l}\text { Mission difficulty is } \\
\text { indicated by diamonds }\end{array}$ & $\begin{array}{l}\text { The ability to change } \\
\text { the difficulty settings } \\
\text { mid-game. }\end{array}$ & $\begin{array}{l}\text { Hardest version of CS series, } \\
\text { require the most skill out of } \\
\text { all the games }\end{array}$ \\
\hline $\begin{array}{l}\text { Voice Acting } \\
\text { quality }\end{array}$ & $\begin{array}{l}\text { Amazing and A high- } \\
\text { pitched keening sound }\end{array}$ & Ambient sound effects & $\begin{array}{l}\text { Incredible visuals } \\
\text { and sound to go } \\
\text { along with actions }\end{array}$ & Inconsistent voice acting & Acceptable quality & Finest quality \\
\hline $\begin{array}{l}\text { Music } \\
\text { soundtrack }\end{array}$ & $\begin{array}{l}\text { Light melodic music } \\
\text { playing constantly in the } \\
\text { background is great }\end{array}$ & $\begin{array}{l}\text { Incredibly } \quad \text { successful } \\
\text { soundtrack }\end{array}$ & Bold and majestic & $\begin{array}{l}\text { Best music, extremely } \\
\text { enjoyable }\end{array}$ & $\begin{array}{l}\text { Dark and powerful } \\
\text { instrumental enhances } \\
\text { the action and emotion } \\
\text { of the gaming } \\
\text { experience }\end{array}$ & Energetic and cinematic \\
\hline $\begin{array}{l}\text { Background } \\
\text { noises }\end{array}$ & $\begin{array}{l}\text { Background noises } \\
\text { enhances the story }\end{array}$ & Constant buzzing noise & $\begin{array}{l}\text { The music fits nicely } \\
\text { with the game but } \\
\text { not overwhelming }\end{array}$ & $\begin{array}{l}\text { Background is louder } \\
\text { than the cut scene } \\
\text { dialogues }\end{array}$ & Ambient sounds & Satisfying but heavy noises \\
\hline Image Quality & $\begin{array}{l}\text { The very high quality } \\
\text { image is stunning, the } \\
\text { textures are impressive, } \\
\text { lighting is great }\end{array}$ & $\begin{array}{l}\text { Image quality improves } \\
\text { by running the game at } \\
\text { high resolutions }\end{array}$ & $\begin{array}{l}\text { HD graphics and } \\
\text { high resolution } \\
\text { textures }\end{array}$ & $\begin{array}{l}\text { Better but could have } \\
\text { been best }\end{array}$ & High resolution images & $\begin{array}{l}\text { Realistic and highly crisp } \\
\text { graphical images }\end{array}$ \\
\hline
\end{tabular}




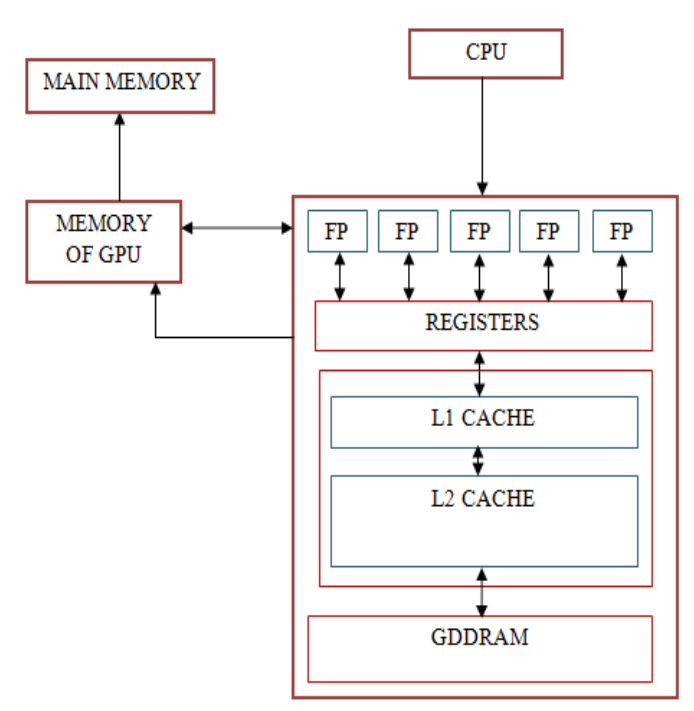

Fig. 6. Working flow of GPGPU

GPU architecture is alike to a many-core processor, which accomplishes higher performance on parallel code which is on the contrary with multi-core CPUs, containing finest single-thread performing cores. GPUs are chiefly upgraded for 2D arrays. Caches inherited on the GPU are shared in a great extent by fragment processors (FP).

GPU kernel code is also loaded on CPU. For superior performance, data movement from main memory to the GPU should be averted. On completing the computation, GPU copies the data back to the CPU memory. All SM is coupled with a personal L1 Data Cache and stable caches along with a shared scratchpad memory as shown in figure 6 .

\section{A. Improving Game Engine Performance in Terms of Task and Data Level Parallelism}

A contemporary game engine is usually encompasses user input, game logic, artificial intelligence (AI), physics, audio and graphics. A renderer is needed for $2 \mathrm{D} / 3 \mathrm{D}$ graphics.

Lately popularized CUDA/GPGPU computing possesses the capability to amplify the acceleration persistently [15]. Though the GPU was produced to quickly maneuver and modify memory to expedite the formation of images in a frame buffer aimed for output display, GPGPU computing is now bestowing excellent performance by unloading exhaustive computation component of the application, whereas the remaining code executes on the CPU.

Games are innately serialized making multithreaded application intricate to run. The initial attempt made in the game engine was to simultaneously run the client and the server on the individual cores respectively by means of coarse grained threading mechanism. Thus, GPGPU has now become a vital component of today's conventional computing systems. In [11], four GPGPU triumphs in game physics and computational AI succeed above the optimized CPU applications. Since games have become progressively restricted by CPU performance, divesting intricate CPU jobs to the GPGPU concedes improved overall performance.

Task parallelism is employed in a game engine by executing each module task in its individual thread [12-14]. Graphics renderer and physics model are good for laterally analogous because of their processor-severe tasks. In a game engine, data parallelism allows similar category of data in a module to run parallel in several threads. This scheme balances fine for a huge figure of processors because of the reason that, the magnitude of the data running on each thread is partitioned uniformly. Communication overhead can be reduced by grouping the application objects that might interact within the same thread.

\section{B. Improving Game Engine Performance in Terms of Physics and $A I$}

GPU currently offer hardware acceleration for physics transformation, sustaining amassed general computation. This conception is recognized as General Purpose processing on Graphics Processing Unit. Latest AMD and NVIDIA graphics cards enables base for rigid body dynamics computations. When such style of hardware acceleration is unavailable, Physics computations are implemented in software which causes inferior CPU-confined performance. Development of PhysX engine articulates on the GPGPU competence of modern GPUs. GPU's are the best room to work out physics calculations for the reason that, physics execution is propelled by thousands of concurrent calculations and execution. These days, NVIDIA's GPUs, is having as many as 480 cores, complementarily profits PhysX engine. NVIDIA is dedicated to create the gaming experience and gameplay exhilarating, lively, and vibrant [27].

The subsequent huge obsession for GPGPU processing is AI [30], to be confronted in games. In 2005, an Israeli company called AIseek proclaimed a devoted processor called the Intia, which was created to speed up various AI characteristics. This makes AI to be an element of a customary PC, thus making AI a suitable preference in view of GPGPU technology. nearly every player has a graphics card compatible with Nvidia's CUDA or AMD's Stream technology, it may possibly take even a little of the total load from the CPU while processing recurring AI tasks and features. Even a minute segment of a GPU's resources enhances AI processing power for several jobs. Possibly OpenCL or DirectX 11's Compute Shader, might present a method to speed up AI on extensive GPU array. Moreover, it seems as AI possibly can be a chief progression in GPGPU processing.

Concerning the cutting edge cloud computing, most of the computations are eventually carried out by multi-core CPUs and manycore GPUs, despite of their allocation. GPGPU cloud computing [16$21,24]$ is more broadly applicable, offering general purpose computing ability in the manner of on-demand virtual resources. In GPGPU cloud computing, the processing strength of physical resources is divided by virtual resources and summoned obliquely. The whole GPGPU cloud system is separated into three layers with this analysis articulating on the task characteristics, hardware features, scheduling mechanism, and execution mechanism of each layer [cloud].

Disparity in the architectures between CPU and GPU specifies that in order to attain superior performance, code for the GPU must be optimized in a different way. GPU is dedicated for extremely parallel computation and thus premeditated to include more dedicated transistors for data processing more willingly than caching and flow control. More explicitly, the GPU is particularly compatible to deal with tribulations that are articulated as data-parallel computations with intense arithmetic computation. At this point, GPGPU is yet to be an established technology. In the next few years, graphic processors will turn out to be a superior technology, best suited to sustain the cascaded processed applications.

\section{From Advancements To The Future Of Gaming TECHNOLOGY}

Gaming technology has been booming since its exhumed roots of tic-tac-toe, brick-games, snakes and ladders, and chess. In leaps and bounds, digital games have gone from novelties that performed simple tasks, to intricate code that facilitates immersive gameplay experiences. On exploring achievements in gaming world, AI, portability, ubiquitous, open web, 3D, voice and motion controls, one 
can envision how lifelike and experiential video games will get the breakthrough, as the technology progresses.

With enormous investment in designing the next big gaming innovation, the potential of what the futurity of games will bring are infinite.

Game developers have always been adept at combining cutting edge and existing technologies. For instance, movement control gaming achieved a mainstream audience when it amalgamated with the mobile world. And open-world games will be played without any skills to involve players collectively from all over the world by global network. A best mechanism for predicting the future of gaming is to review what is already present and by visualizing the how it could evolve effectively. Just by taking 3D image or augmented reality a step further and then can experience and get pleasure from hologram gaming, an edge that does not give the impression of having any covenance and regulations.

Video games has emanated from a long way ever since they overlapped into the conventional in the 1980 s, but some incredible improvements in the technologies made the future of gaming even dazzling. 3D scanning and facial recognition technology has permitted developers to actually develop their likeness in the game or to ingeniously transfer their expressions to additional digital creations. For example, Intel's RealSense 3D camera allows gaming developers to produce games adapting the emotions of the gamer by scanning different locations of a player's face.

Voice controlled gaming has remained all over the place for a while, but the prospective of using this technology in gaming systems has finally captivated to realism, now even computers are capable to effortlessly diagnose voice commands from the player. Player can now turn the game console on and off, supervise gameplay, interact on social game group, all by commanding to your gaming system. Using a 3D camera that trails distinct area of your body, gesture control consents players to connect to their gaming experience by means of the usual body movements. State of the art advancements deliver to players a rich and high quality experience in form of fully rendered worlds with photo realistic textures.

Whether it's smart watches or goggles, wearable games make gaming mobile without being too intrusive. Wearable games are extensions of the body in addition to extensions of the consoles used while playing. With the dawn of smartphones, the entire gaming experience is now in the hand of the players. Instead of developing gaming structures necessitating more influential hardware, developers have lessened the load with the use of cloud computing. By usage of clouds, game streaming is now a reality, streaming similar to movie streaming.

However many Virtual Reality (VR) gaming consoles are not released commercially yet, but this developing VR technology is dignified to concede gamers a wholly immersive gaming experience. VR are sometimes stated as immersive multimedia or computersimulated reality duplicates environs by simulating a corporeal existence at places in the physical-world or a fantasy world, letting the players to communicate with that world within the simulated environment. Virtual Reality is imminent. It's no overstatement to state that VR is one of the gigantic advancements in gaming world and eradicating the blockade in the midst of player and game world.

Augmented reality gaming starts to take hold through smartphones and glasses technology from the likes of Google. Till 2025, Virtual reality simulations embarks on to turn out to be feasible in the home market, and unlike the augmented reality techniques that have been in favor for the last ten years these will begin to feature fully immersive systems. These experiences will still experience to some extent disconnected from realism though, as control mechanisms will require various forms of static activity. Graphics and physics technology by this stage will be able to perfectly mimic real-world resolutions and depth, with added emergent behavioral algorithms allowing sandbox gaming and interaction with characters and environments that promote personally crafted narrative experiences.

\section{CONCLUSION}

From the commencement of game engines to the latest 3D jazzedup game engines, the objective of development was to endure the equivalent i.e. giving game coders a rostrum for creating their unique games into reality. These engines offer the rudimentary central design with codes and the manifestation as a middleware. The progression of gaming engines is at the present are proceeding en route for supplementary realistic and technically sound games in innumerable grounds like physics, sounds, AI, graphics, and animations etc. from the analysis it can be stated that, Max Payne 3 is rich to deliver high and crisp graphics but is costly in terms of memory whereas Crysis 3 bestows better CPU utilization. Max Payne 3 has high level of emotional intelligence compared to other games, engaging the player's in the gameplay.

Future machines will be progressively more assorted. Individual processor chips will probably enclose processing component with diverse functioning features, memory hierarchy, and levels of physical concurrency. Till 2018, it can anticipated that GPU's will no longer be an external driving force of CPU; rather, both CPU's and GPU's will be incorporated by the same dye through a unified memory architecture..

\section{ACKNOWLEDGMENT}

We wish to thank all the students, game player's and game developers around the country who actively contributed in this comparative analysis.

\section{REFERENCES}

[1] Julie Wilmore, "Dissecting the Video Game Engine and a Brief History", Retrieved From: juliewilmore.files.wordpress.com/2010/07/ tc339finalpaper.pdf.

[2] Kuan-Ta Chen et al, "On the Quality of Service of Cloud Gaming Systems" Published in IEEE Transactions on Multimedia, Volume: 16, Issue: 2, 19 November 2013, 480 - 495 .

[3] Kowit Rapeepisarn et al, "A Comparative Study of Digital Game Platforms for Educational Purposes", Published in Ninth Postgraduate Electrical Engineering and Computing Symposium, 4th November 2008, Perth, W.A. pp. 37-40 Chen, Linear Networks and Systems (Book style). Belmont, CA: Wadsworth, 1993, pp. 123-135.

[4] Michael Jarschel, et al., "Gaming in the clouds: QoE and the users perspective", Published in Mathematical and Computer Modelling, Volume 57, Issues 11-12, June 2013, Pages 2883-2894.

[5] Rahma Gharsallaoui et al, "A comparative Study on Cloud Gaming Platforms", Published in 7th International Conference on Control and Automation, 20-23 Dec. 2014, pp 28-32.

[6] Chun-Ying Huang et al, "GamingAnywhere: An Open Cloud Gaming System", Published in MMSys Proceedings of the 4th ACM Multimedia Systems Conference, Pages 36-47, pp 36-41

[7] Ryan Shea et al, "Cloud Gaming: Architecture and Performance" Published in IEEE Network, Volume 27, Issue 4, July-August 2013, 16-21.

[8] Georgios N. Yannakakis, John Hallam, Henrik Hautop Lund, "Comparative Fun Analysis in the Innovative Playware Game Platform", Published in Proceedings of the $1^{\text {st }}$ World Conference for Fun ' $n$ Games 2006, pp. 6470.

[9] M. Joselli and E. Clua, "Gpu wars: Design and implementation of a GPGPU game," Published in Proceedings of the 8th Brazilian Symposium on Games and Digital Entertainment, Brazil, October, 8th-10th 2009.

[10] Richard M. Ryan • C. Scott Rigby • Andrew Przybylski, "The Motivational Pull of Video Games: A Self-Determination Theory Approach”, Published in Springer Journal of Motivation and Emotion, December 2006, Volume 
30, Issue 4, pp 344-360.

[11] Owens, J.D., Houston, M., Luebke, D., Green, S., Stone, J.E. \& Phillips, J.C. "GPU Computing: Graphics Processing Units-Powerful, Programmable and Highly Parallel-Are Increasingly Targeting General -Purpose Computing Applications", Published in Proceedings of the IEEE, pp. 879-899, 2008.

[12] Ooste, J.V., 3D Game Engine Programming: Helping You Build Your Dream Game Engine, 2011, Published online at http://3dgep. com/?p=1821,1 August 2013 .

[13] Guevara, M., Gregg, C., Hazelwood, K., \& Skadron, K., "Enabling Task Parallelism in the CUDA Scheduler", Published in IEEE PEMA. 2009.

[14] Baumstark, L.Jr. \& Wills, L., Exposing Data - Level Parallelism in Sequential Image Processing Algorithms, Published in Proceedings of the Ninth Working Conference on Reverse Engineering (WCRE'02), IEEE, 2002.

[15] Designing the Framework of a Parallel Game Engine (PGE), Intel, Published online: http://www.intel.com (1 August 2013).

[16] Liang Hu, Xilong Che and Zhenzhen Xie, "GPGPU Cloud: A Paradigm for General Purpose Computing", Published in Journal of Tsinghua Science And Technology, ISSN:1007-02141 103/12, pp22-33, Volume 18, Number 1, February 2013.

[17] J. Nickolls and W. J. Dally, "The GPU computing era", Published in IEEE Micro., vol. 30, no. 2, pp. 56-69, March-April 2010.

[18] L. Shi, H. Chen, J. Sun, and K. Li, "CUDA: GPU-accelerated highperformance computing in virtual machines", Published in IEEE Transactions on Computers, vol. 61, no. 6, pp. 804-816, June 2012.

[19] V. Gupta, A. Gavrilovska, K. Schwan, H. Kharche, N. Tolia, V. Talwar, and P. Ranganathan, "GViM: GPU-accelerated virtual machines", Published in Proceedings of the 3rd ACM Workshop on System-Level Virtualization for High Performance Computing (HPCVirt 09), Nuremberg, Germany, March 31, 2009, pp. 17-24.

[20] C. Yang, C. Huang, C. Lin, and T. Chang, "Hybrid parallel programming on GPU clusters", Published in Proceedings of the IEEE International Symposium on Parallel and Distributed Processing with Applications (ISPA 2010), Taipei, China, September 6-9, 2010, pp. 142-147.

[21] V. V. Kindratenko, J. J. Enos, G. Shi, M. T. Showerman, G. W. Arnold, J. E. Stone, J. C. Phillips, and W. Hwu, "GPU clusters for high-performance computing", published in Proceedings of the 2009 IEEE International Conference on Cluster Computing (CLUSTER 2009), New Orleans, Louisiana, USA, August 31-September 4, 2009, pp. 1-8.

[22] John D. Owens et al., "GPU Computing", Published in Proceedings of the IEEE, Volume: 96, No. 5, May 2008.

[23] William Blewitt, Gary Ushaw, and Graham Morgan, "Applicability of GPGPU Computing to Real-Time AI Solutions in Games", Published in IEEE Transactions on Computational Intelligence and $\mathrm{AI}$ in Games, April $11,2013$.

[24] R. Shea, Simon Fraser, "On GPU pass-through performance for cloud gaming: Experiments and analysis", Published in IEEE 12th Annual Workshop on Network and Systems Support for Games (NetGames), pp. 1 - 6, Denver, CO, USA, 9-10 Dec. 2013.

[25] Mark Joselli et al., "A new physics engine with automatic process distribution between CPU-GPU', Published in Proceeding Sandbox '08 ACM SIGGRAPH symposium on Video games, pp.149-156.

[26] M. Mittring and B. Dudash, "The technology behind the directx 11 unreal engine "samaritan" demo," Published in Proceedings of Game Developers Conference 2011.

[27] AIseek, "AIseek - intelligence for new worlds," White Paper, 2006

[28] E. Lindholm, J. Nickolls, S. Oberman, and J. Montrym, "Nvidia tesla: A unified graphics and computing architecture," Published in IEEE Micro, vol. 28, no. 2, pp. 39-55, 2008.

[29] NVIDIA, "Nvidia's next generation cuda compute architecture: Kepler gk110," White Paper, 2012

[30] C. J. Darken, E. R. Pursel, and J. S. Correia, "AI on the GPU," Published in ACM Workshop on General Purpose Computing on Graphics Processors, 2004.

[31] J. D. Owens, D. Luebke, N. Govindaraju, M. Harris, J. Kr"uger, A. E. Lefohn, and T. J. Purcell, "A survey of general-purpose computation on graphics hardware," Published in Journal of Computer graphics forum, Blackwell Publishing Ltd, pp. 80-113, 2007.

[32] D. Kirk, "Nvidia CUDA software and GPU parallel computing architecture," Published in Proceedings of the ACM 6th International Symposium on Memory Management, Montreal, Canada - October 21 $-22,2007$.

[33] G. Gunasekaran, "Study of performance for the CPU and GPU architecture," Published in International Journal of Research in IT, Management and Engineering, vol. 2, no. 2, pp. 33-44, February 2012.

[34] X. Zhang, B. Wang, and C. Geng, "Gpu-based background generation method," Published in Proceedings of the IET International Communication Conference on Wireless Mobile and Computing (CCWMC 2011), 2011.

[35] ] C. Gregg and K. Hazelwood, "Where is the data? Why you cannot debate CPU vs. GPU performance without the answer," Published n Proceedings of the IEEE International Symposium on Performance Analysis of Systems and Software (ISPASS '11), Washington, DC, USA, pp. 134-144, 2011.

[36] Raúl Lara-Cabrera, Mariela Nogueira-Collazo, Carlos Cotta, Antonio J. Fernández-Leiva, "Procedural Content Generation for Real-Time Strategy Games", Published in Special Issue on Digital Economy, International journal of Interactive Multimedia and Artificial Intelligence, Vol. 3, No 2, 2014.

[37] Arranz, Á., and M. Alvar, "GPGPU Implementation of a Genetic Algorithm for Stereo Refinement", Published in Special Issue on Digital Economy in International Journal of Interactive Multimedia and Artificial Intelligence, ISSN 1989-1660, pp. 69-76, March 2015.

[38] Holman Bolívar Baron, Sandra Castillo Salinas ; Rubén Gonzalez Crespo, "An approach to assessment of video game-based learning using structural equation model", Published in IEEE $9^{\text {th }}$ Iberian Conference on Information Systems and Technologies (CISTI), Barcelona, 18-21 June 2014.

[39] Lara-Cabrera, R., M. Nogueira-Collazo, C. Cotta, and A. J. FernándezLeiva, "Procedural Content Generation for Real-Time Strategy Games", Published in Special Issue on Digital Economy in International Journal of Interactive Multimedia and Artificial Intelligence, ISSN 1989-1660, pp 40-48, March 2015.

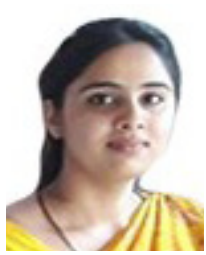

Ms. Prerna Mishra has completed her M. Tech degree in Computer Science \& Engg from G.H. Raisoni College of Engineering, Nagpur. She is presently working as Assistant Prof in CSE Dept, J. D. College of Engineering, Nagpur, India. Her area of interest includes Assistive Technology and Human Computer Interaction. She is member of various professional bodies like IEEE, IAENG, UACEE, IACSIT, CSI, ICST, ISTE.

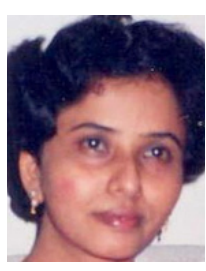

Dr. Urmila Shrawankar completed her Ph.D. degree in Computer Science and Engg from SGB Amravati University and M. Tech. degree in Computer Science \& Engg from RTM Nagpur University. She is presently working as Associates Prof. in CSE Dept, G H Raisoni College of Engineering, Nagpur, India. Her area of interest includes Advanced Operating Systems, High performance Computing, Distributed and Parallel computing, Cloud Computing, Algorithms, Assistive Technology etc. She has many research publications in refereed international journal and conferences in her account with good number of citations. She is a receiptant of DST Travel Grant from Govt. of India, Ministry of Science \&amp; Technology for attending Springer - International Conference at Manchester, UK, Year 2010 and UGC Minor Project Grant. She is a reviewer of many refereed Inter-National journals and has worked as a core organizing committee member, Technical program committee member and Session Chair at many international conferences. She is Member of various Professional bodies like IEEE, ACM, CSI, ISTE, IE. Under her guidance 22 B.E (CSE) project groups, $60 \mathrm{M}$. Tech (CSE) project scholars and $03 \mathrm{PhD}$ Research scholars are working and completed their projects. 